\title{
GERMINAÇÃO DO EUCALIPTO E ESPÉCIES BIOINDICADORAS SOB O USO DE DOIS BIOFERTILIZANTES
}

\author{
Gislayne de Araujo Bitencourt ${ }^{1}$, Suzana Lopes Costa², João Maria lavorski \\ Junior $^{3}$, Brendha Barba Algarve ${ }^{4}$ e Rosana Moreira da Silva de Arruda ${ }^{5}$
}

\begin{abstract}
Resumo: Os biofertilizantes apresentam-se como uma alternativa de aproveitamento dos dejetos animais como fertilizantes na agricultura. Com base nisso, objetivou-se avaliar o efeito de dois biofertilizantes de origem animal tratados em biodigestor por meio de teste ecotoxicológico utilizando as espécies bioindicadoras Allium cepa L. (cebola); Eruca sativa L. (rúcula) e Lactuca sativa L.(alface) para posteriormente testar a mesma metodologia em Eucalyptus camaldulensis Dean. (eucalipto) empregando os métodos de germinação e crescimento de plântulas. Para tanto, soluções com o sobrenadante dos biofertilizantes em concentrações de: 0; 12,5; 25; 50; 75 e 100\% foram preparadas. Para avaliar a germinação, vinte sementes de cada espécie foram acondicionadas em uma caixa gerbox contendo papel filtro, umedecido com a solução de biofertilizante. Os testes foram realizados com três repetições, distribuídas em um delineamento inteiramente casualizado (DIC) em fatorial $6 \times 2 \times 3$, com temperatura controlada a $25^{\circ} \mathrm{C}$ e fotoperíodo de 12 horas, por cinco dias. Para o eucalipto aplicou-se a mesma metodologia, em DIC fatorial $6 \times 2$, utilizando $0,10 \mathrm{~g}$ de sementes, a $28^{\circ} \mathrm{C}$, por 14 dias. Não foram verificados efeitos de toxicidade sobre a germinação e o crescimento inicial das plântulas de alface e rúcula. No eucalipto, a solução contendo $100 \%$ de biofertilizante ovino promoveu aumento no crescimento das plântulas.
\end{abstract}

Palavras-chave: Bovino. Ovino. Dejetos. Toxicidade.

\section{Introdução}

A produção animal é uma das atividades econômicas com grande geração de resíduos com potencial poluidor. Os prejuízos ambientais causados pela falta de tratamento e manejo adequado dos resíduos são enormes, poluindo recursos hídricos e o solo. Em virtude disso, a busca por insumos menos agressivos ao ambiente, que possibilitem a reutilização dos resíduos oriundos da produção animal na agricultura, são desejáveis. Principalmente, visando uma produção agrícola mais sustentável, com menor uso de produtos químicos industrializados (JÚNIOR et al., 2011; BARBOSA; LANGER, 2011). Esses resíduos quando tratados em biodigestores, tornam-se insumos agrícolas com grande valor agregado, reduzindo os custos com insumos químicos e são reutilizados na reciclagem dos nutrientes, promovendo aumentos na produtividade agrícola (MEDEIROS et al., 2007). Para tanto, esses resíduos precisam ser transformados em biofertilizantes, por meio do processo de digestão anaeróbica, gerando um produto de grande valor para a agricultura. Os biofertilizantes, podem ser utilizados como adubos na agricultura e nas pastagens, por serem ricos em matéria orgânica com grande potencial de fertilização (BARBOSA; LANGER, 2011).

Este composto atua diretamente sobre a matéria orgânica, gerando um efeito floculante no solo, formando uma camada de impedimento às perdas elevadas de água por evaporação, melhorando o movimento do ar, da água e dos nutrientes e favorecendo o crescimento e penetração das raízes no solo (CAVALCANTE et al., 2010).

Segundo Fuentes et al. (2004) para se investigar a possibilidade de aplicação de um resíduo no solo é necessária a avaliação de sua toxicidade $\mathrm{e}$, neste contexto, os organismos-teste mais utilizados são plantas. Os testes ecotoxicológicos padronizados pela Associação Brasileira de Normas Técnicas (ABNT), avaliam a contaminação de solos por

\footnotetext{
1E-mail: gislaynebitencourt@gmail.com

2E-mail: suzanalopescosta@hotmail.com

33E-mail: joaoiavorski@gmail.com

${ }^{4}$ E-mail: deda.algarve@gmail.com

${ }^{5}$ E-mail: rosana.msilva@uol.com.br
}

Universidade Estadual de Mato Grosso do Sul - UEMS, Unidade Universitária de Aquidauana 
meio de testes utilizando plantas bioindicadoras que visam a complementação da análise química, que busca conhecer a consequência da liberação de substâncias químicas diretamente sobre as plantas, por meio do monitoramento de efeitos letais, morfológicos e fisiológicos (ISO 11269-2, 2014).

As espécies Allium cepa L. (cebola); Eruca sativa L. (rúcula); e Lactuca sativa L. (alface) são utilizadas em testes ecotoxicológicos, por serem consideradas planta modelo, padronizadas internacionalmente, úteis na avaliação da fitoxicidade, por apresentarem germinação rápida e uniforme, além de expressarem resultados em baixas concentrações de substâncias tóxicas (BARSZCZ et al., 2019; RAMIRES et al., 2019; AZAMBUJA et al., 2010).

Diante do exposto, objetivou-se avaliar o efeito de dois biofertilizantes de origem animal, um biofertilizante originário de bovino e outro biofertilizante originário de ovino. Os dois biofertilizantes foram tratados em biodigestor por meio de teste ecotoxicológico utilizando as espécies bioindicadoras Allium Cepa L.; Eruca sativa L. e Lactuca sativa L.. Posteriormente a mesma metodologia foi testada em Eucalyptus camaldulensis Dehn. empregando os métodos de germinação e crescimento de plântulas.

\section{Metodologia}

Os experimentos foram conduzidos no Laboratório de Fitossanidade e os biofertilizantes foram cedidos pelo Laboratório de Tratamento de Resíduos da Universidade Estadual de Mato Grosso do Sul - UEMS.

Os biofertilizantes foram produzidos utilizando biodigestores tipo batelada, com capacidade de 2 litros de substrato em fermentação. Os mesmos, foram abastecidos com água + dejetos contendo aproximadamente $6 \%$ de sólidos totais (m:v) e foram operados com tempo de retenção hidráulica (TRH) de 90 dias em condições anaeróbias. O efluente final foi caracterizado para sólidos totais (ST) e sólidos fixos (SF) (Tabela 1).

Os biofertilizantes foram caracterizados quanto ao $\mathrm{pH}$ e a condutividade elétrica utilizando um pHmetro e condutivímetro conforme metodologia proposta por Abreu et al. (2009). A quantificação de nitrogênio foi realizada de acordo com o método de digestão com $\mathrm{H}_{2} \mathrm{SO}_{4}$ $+\mathrm{H}_{2} \mathrm{O}_{2}$ e destilação de Kjeldahl conforme Miyazama et al. (2009) e de fósforo disponível de acordo com o método de Mehlich 1, a leitura foi realizada utilizando um espectrofotômetro no comprimento de onda de $660 \mathrm{~nm}$ de acordo com Silva et al. (2009). A matéria orgânica foi quantificada com base no método de Walkley-Black segundo Embrapa (1997). E a quantificação de coliformes totais e termotolerantes foi realizada por meio do teste de tubo múltiplo conforme Soares e Maia (1999).

Tabela 1 - Caracterização do biofertilizante bovino e ovino para sólidos totais e fixos

\begin{tabular}{lcc} 
& $\mathrm{ST}\left(\mathrm{g} \mathrm{kg}^{-1}\right)$ & S Fixo $\left(\mathrm{g} \mathrm{L}^{-1}\right)$ \\
\hline Bovino & 114,4 & 37,90 \\
Ovino & 96,2 & 43,41 \\
\hline \multicolumn{3}{c}{ ST= sólidos totais SF= sólidos fixos } \\
\multicolumn{3}{c}{ Fonte: Autores (2021) }
\end{tabular}

Os biofertilizantes foram diluídos numa proporção de 1:4 com água deionizada, separadamente, em seguida foram agitados por duas horas em mesa agitadora orbital e descansaram a uma temperatura de $4^{\circ} \mathrm{C}$ por 24 horas. Após isso, foram centrifugados por 5 min e coletado o sobrenadante da solução.

Foram realizados dois experimentos, o primeiro com sementes de três espécies bioindicadoras: Allium Cepa L cv. cebola periforme; Eruca sativa L. cv. rúcula cultivada e Lactuca sativa L. CV. aurélia, o segundo experimento foi realizado com sementes de $E$. camaldulensis cv. LCFA 014.

As sementes das três espécies bioindicadoras foram distribuídas em caixa gerbox contendo papel filtro como substrato, umedecido com $7 \mathrm{~mL}$ nas seguintes concentrações: $0 ; 12,5 ; 25 ; 50 ; 75$ e $100 \%$ de solução de cada biofertilizante e um controle negativo com $\mathrm{NaCl} 1,0 \mathrm{~N}$. O NaCl é utilizado para validar o ensaio, pois sua alta concentração promove a inibição da germinação da semente.

As sementes foram distribuídas em duas fileiras de 10, totalizando 20 sementes de cada espécie bioindicadora, em cada caixa, com três repetições para cada concentração e espécie. $O$ delineamento utilizado foi inteiramente casualizado (DIC) em fatorial $6 \times 2 \times 3$ (concentrações $x$ biofertilizantes $x$ espécies). As caixas foram mantidas em câmara de germinação tipo BOD com temperatura controlada $25 \pm 2^{\circ} \mathrm{C}$ e fotoperíodo de 12 horas, por um período de cinco dias. 
Para o ensaio com E. camaldulensis utilizou-se a metodologia por meio de pesagem das sementes conforme proposto pela RAS (Regras para Análises de Sementes) (BRASIL, 2009), devido à baixa taxa de pureza das mesmas, pois em muitas espécies é impossível diferenciar com segurança a semente dos óvulos não fertilizados ou os que não se desenvolveram numa semente madura. Nesse caso utilizouse 0 teste de sementes por repetições pesadas. Utilizou-se $0,10 \mathrm{~g}$ de sementes de E. camaldulensis em cada gerbox, distribuídas em três fileiras, com três repetições para cada concentração. As caixas foram distribuídas em DIC fatorial $6 \times 2$ (concentrações $x$ biofertilizantes), foram mantidas em câmara de crescimento tipo $\mathrm{BOD}$ com temperatura controlada $28 \pm 2^{\circ} \mathrm{C}$ e fotoperíodo de 12 horas, por um período de 14 dias.

Ao final dos experimentos, foram determinadas as porcentagens de germinação, comprimento de raiz (CR) e de parte aérea das plântulas (CPA).
Os dados obtidos dos dois experimentos foram submetidos a análise de variância (teste $F$ ) e as médias foram comparadas por meio do teste de Tukey $(p<0,05)$ utilizando o programa estatístico SAS.

\section{Resultados}

\subsection{Caracterização dos biofertilizantes}

A despeito da caracterização química dos biofertilizantes, pode-se inferir que os valores de $\mathrm{pH}$ dos biofertilizantes mostraramse adequados à faixa de $\mathrm{pH}$ considerada ideal em relação às exigências biológicas fixados pela resolução $n^{\circ} 430$ (CONAMA, 2011), que define como padrão $\mathrm{o} \mathrm{pH}$ entre 5 e 9 . Entretanto, a elevada condutividade elétrica (CE) verificada no biofertilizante bovino indica alta concentração de íons, conforme Lawlor et al. (2004) a faixa de 4 a $8 \mathrm{mS} \mathrm{cm}^{-1}$ interfere na produtividade de muitas culturas (Tabela 2 ).

Tabela 2 - Caracterização dos atributos dos dois biofertilizantes

\begin{tabular}{|c|c|c|c|c|c|c|c|}
\hline & $\begin{array}{c}\mathrm{pH} \\
\mathrm{H}_{2} \mathrm{O}\end{array}$ & $\begin{array}{c}\mathrm{CE} \\
\mathrm{mS} \mathrm{\textrm {cm } ^ { - 1 }} \\
\end{array}$ & $\begin{array}{c}\mathrm{N} \\
\mathrm{g} \mathrm{kg}^{-1}\end{array}$ & $\begin{array}{c}\mathrm{P} \\
\mathrm{mg} \mathrm{dm^{-3 }} \\
\end{array}$ & $\begin{array}{c}\mathrm{MO} \\
\mathrm{g} \mathrm{kg}^{-1}\end{array}$ & $\begin{array}{c}\text { CTO } \\
100 \mathrm{~g} \mathrm{~mL}^{-1}\end{array}$ & $\begin{array}{c}\text { CTE } \\
100 \mathrm{~g} \mathrm{~mL}^{-1}\end{array}$ \\
\hline Ovino & 8,10 & 2,60 & 24,08 & 38,54 & 28,19 & $1,5.10^{-2}$ & $0,3 \cdot 10^{-2}$ \\
\hline Bovino & 8,57 & 6,83 & 22,89 & 175,01 & 28,19 & $2,5.10^{-2}$ & $0,4 \cdot 10^{-2}$ \\
\hline
\end{tabular}

$\mathrm{pH}=$ potencial hidrogênio iônico; $\mathrm{CE}=$ condutividade elétrica; $\mathrm{N}=$ nitrogênio amoniacal; $\mathrm{P}=$ fósforo disponível; $\mathrm{MO}=$ matéria orgânica; $\mathrm{CTO}=$ coliformes totais; $\mathrm{CTE}=$ coliformes termotolerantes Fonte: Autores (2021)

A condutividade elétrica é um parâmetro que precisa ser monitorado, visto que elevadas concentrações de sais prejudicam a germinação das sementes. Segundo Khadri et al. (2006), a alta concentração de sais provoca a redução do processo fotossintético, ocasionando o aumento da respiração, prejudicando o crescimento. A concentração de nitrogênio é semelhante nos dois biofertilizantes. Entretanto, a quantidade de fósforo é mais elevada no fertilizante bovino, sendo $78 \%$ maior do que o ovino.

Com base nos parâmetros avaliados nos biofertilizantes, eles foram considerados adequados para o cultivo vegetal (KIEHL, 2012).

\subsection{Testes de germinação com as espécies bioindicadoras}

A porcentagem de germinação não diferiu estatisticamente entre as concentrações testadas nas três espécies e entre os dois biofertilizantes, mesmo os biofertilizantes apresentando elevada condutividade elétrica não interferiram na germinação das sementes. Não foram observadas sementes germinadas na concentração de $\mathrm{NaCl}$ validando o ensaio (Figura 1).

Resultados semelhantes a esse experimento, foram citados por Barszcz et al. (2019) realizando um teste ecotoxicológico avaliando a germinação de alface utilizando efluente doméstico, os autores não verificaram diferença estatística na germinação.

Foi verificada diferença significativa $(p<0,05)$ nas concentrações de biofertilizantes e espécies. Não foram observadas diferenças estatísticas entre os biofertilizantes para todas as variáveis avaliadas. Houve interação entre concentração $x$ espécie $e$, concentração $x$ biofertilizante $x$ espécie (Tabela 3 ). 
REA - Revista de estudos ambientais (Online)

v.23, n. 1, p.37-45, jan./jun. 2021

Figura 1 - Germinação de alface, cebola e rúcula submetidas a diferentes concentrações de biofertilizantes bovino e ovino

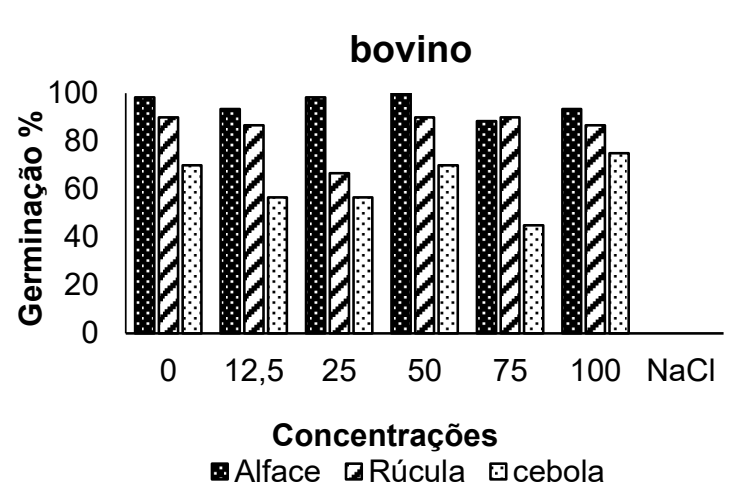

Fonte: Autores (2021)

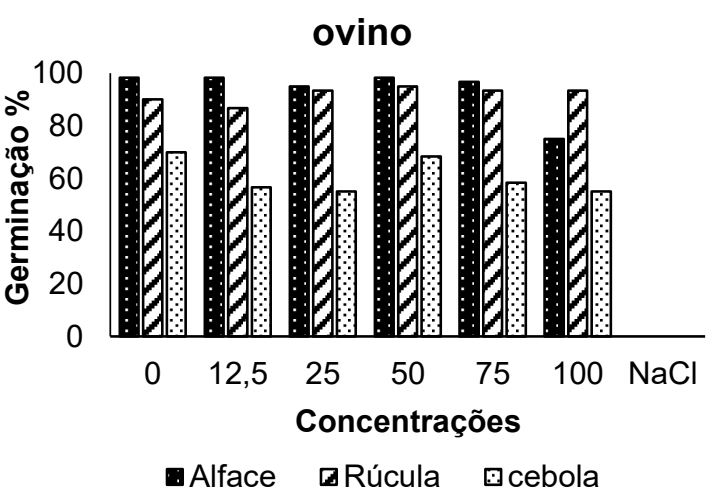

- Alface $\square$ Rúcula घcebola

Tabela 3 - Resumo da análise de variância para crescimento, em centímetros, da raiz (CR) e da parte aérea (CPA) de alface, cebola e rúcula submetidas a diferentes concentrações $(0,12,5 ; 25 ; 50 ; 75$ e $100 \%$ ) de biofertilizante ovino e bovino

\begin{tabular}{lccccc}
\hline & \multicolumn{3}{c}{ CR } & \multicolumn{2}{c}{ CPA } \\
\cline { 2 - 6 } Fontes de variação & GL & QM & P & QM & P \\
\hline Concentração & 5 & 121,07 & $<0,0001^{*}$ & 9,26 & $<0,0001^{*}$ \\
Biofertilizante & 1 & 0,84 & $0,4258^{\text {ns }}$ & 0,31 & $0,412^{\text {ns }}$ \\
Espécie & 2 & 1674,86 & $<0,0001^{*}$ & 197,07 & $<0,0001^{*}$ \\
Concentrações x Biofertilizante & 5 & 2,86 & $0,8255^{\text {ns }}$ & 1,84 & $0,0013^{\text {ns }}$ \\
Concentração x Espécie & 10 & 105,56 & $<0,0001^{*}$ & 13,74 & $<0,0001^{*}$ \\
Concentração x Biofertilizante x Espécie & 12 & 185,11 & $<0,0001^{*}$ & 6,40 & $<0,0001^{*}$ \\
\hline
\end{tabular}

*significativo $(p<0,05) P=p . v a l u e ; G L=$ Grau de Liberdade; $Q M=$ Quadrado médio

Fonte: Autores (2021)

O teste de Tukey verificou diferença significativa $(p<0,05)$ entre a interação (concentrações $x$ espécie) para CR e CPA. $\mathrm{Na}$ interação (concentração $x$ espécies), as três espécies não apresentaram respostas no comprimento de raiz que difeririam do controle. A alface apresentou o maior crescimento de parte aérea na concentração de $75 \%$ e a rúcula nas concentrações de 75 e $100 \%$. Em contrapartida, a cebola apresentou o maior comprimento de parte aérea na concentração controle (Tabela 4).

De modo geral, os biofertilizantes não interferiram na germinação das sementes. Exceto para a cebola que se apresentou como a espécie mais sensível a todas as concentrações dos biofertilizantes, pois o tratamento controle apresentou o maior crescimento de raiz e de parte aérea.

Com relação ao crescimento de parte aérea, alguns trabalhos utilizando biofertilizante expõem seus benefícios. Medeiros et al. (2007) obtiveram maior altura de plantas de três cultivares de alface utilizando composto orgânico contendo biofertilizantes. Sousa et al. (2013), verificaram aumento linear na altura de planta, diâmetro do caule e número de ramos em pinhão-manso pelas concentrações de biofertilizante bovino.

Nascentes et al. (2019) realizaram um teste similar de germinação na espécie de milho, Zea mays, L., espécie bioindicadora conforme a ISO 11269-2 (2014), observaram redução no comprimento de raiz e de parte área quando utilizada a concentração de $100 \%$ do lixiviado de aterro sanitário.

Com base nas observações de Mata et al. (2010) em bioensaio utilizando milho, Zea mays, L., as respostas das plântulas são baseadas no princípio de que os efeitos das substâncias afetam inicialmente a germinação e o desenvolvimento das raízes, pois estas, tem a função de absorção de água e nutrientes, podem afetar positiva ou negativamente. Nesse experimento, a concentração de $100 \%$ ocasionou a redução no crescimento das raízes de alface e rúcula.

De acordo com Oliveira et al. (2010), as diferenças no crescimento tanto de raiz 
como de parte aérea das espécies, podem ser explicadas devido aos divergentes biofertilizantes e suas particularidades referentes a sua composição química, e das concentrações utilizadas. Além disso, as espécies vegetais apresentam diferenças no desenvolvimento e exigência da quantidade e tipos de nutrientes, apresentando respostas positivas ou negativas.

Tabela 4 - Valores médios estimados para a interação (espécie x concentração) para comprimento em centímetros, de raiz (CR) e da parte aérea (CPA) de alface, cebola submetidas as diferentes concentrações $(0 ; 12,5 ; 25 ; 50 ; 75$ e $100 \%)$ de biofertilizante

\begin{tabular}{cccc}
\hline \multicolumn{4}{c}{ Comprimento de raiz (CR) } \\
\hline$\%$ & alface & cebola & rúcula \\
\hline 0 & $2,556 \mathrm{a}$ & $0,740 \mathrm{a}$ & $2,736 \mathrm{a}$ \\
12,5 & $2,072 \mathrm{bc}$ & $0,479 \mathrm{~b}$ & $2,010 \mathrm{~b}$ \\
25 & $2,0366 \mathrm{~b}$ & $0,439 \mathrm{bc}$ & $1,710 \mathrm{~b}$ \\
50 & $2,593 \mathrm{a}$ & $0,452 \mathrm{~b}$ & $2,893 \mathrm{a}$ \\
75 & $2,324 \mathrm{ab}$ & $0,386 \mathrm{c}$ & $3,011 \mathrm{a}$ \\
100 & $1,825 \mathrm{c}$ & $0,532 \mathrm{a}$ & $2,55 \mathrm{~b}$ \\
\hline \multicolumn{4}{c}{ Comprimento de parte aérea (CPA) } \\
\hline 0 & alface & cebola & rúcula \\
\hline 0 & $1,195 \mathrm{c}$ & $0,740 \mathrm{a}$ & $0,891 \mathrm{c}$ \\
12,5 & $1,172 \mathrm{c}$ & $0,446 \mathrm{~b}$ & $1,155 \mathrm{~b}$ \\
25 & $1,5858 \mathrm{~b}$ & $0,497 \mathrm{~b}$ & $0,636 \mathrm{~d}$ \\
50 & $1,591 \mathrm{~b}$ & $0,292 \mathrm{c}$ & $1,320 \mathrm{~b}$ \\
75 & $2,152 \mathrm{a}$ & $0,334 \mathrm{~b}$ & $1,518 \mathrm{a}$ \\
100 & $1,120 \mathrm{c}$ & $0,399 \mathrm{~b}$ & $1,514 \mathrm{a}$ \\
\hline 10 & & & \\
\hline
\end{tabular}

*Médias seguidas de letras iguais não diferem entre si pelo teste de Tukey a 5\% de probabilidade Fonte: Autores (2021)

\subsection{Teste de germinação com Eucalyptus camaldulensis}

No bioensaio utilizando sementes de E. camaldulensis, não foram verificadas diferenças significativas entre as concentrações e os dois tipos de biofertilizantes na germinação. Não foram observadas sementes germinadas na concentração de $\mathrm{NaCl}$ validando o ensaio (Figura 2).

Figura 2 - Germinação de Eucalyptus camaldulensis submetidas a diferentes concentrações de dois biofertilizantes

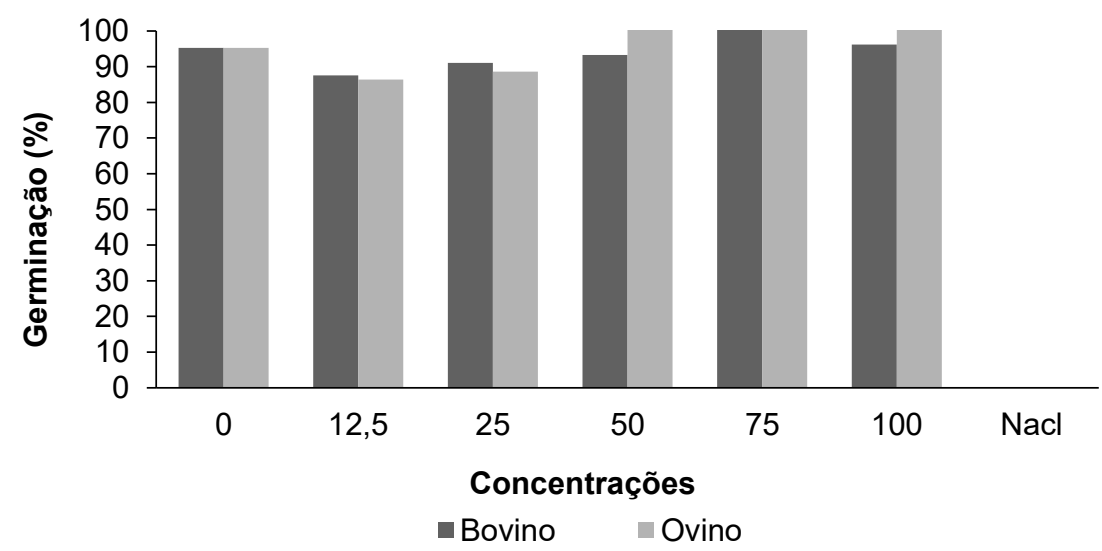

Fonte: Autores (2021) 
Foi verificada diferença significativa $(p<0,05)$ para concentrações, biofertilizantes e interação entre concentração biofertilizante nas variáveis comprimento de raiz e de parte aérea de eucalipto (Tabela 5).

Tabela 5 - Resumo da análise de variância para crescimento, em centímetros, da raiz (CR) e da parte aérea (CPA), de Eucalyptus camaldulensis submetidas a diferentes concentrações $(0,12,5 ; 25 ; 50 ; 75$ e $100 \%$ de biofertilizante ovino e bovino

\begin{tabular}{lcccccc}
\hline \multirow{2}{*}{ Fontes de variação } & \multicolumn{4}{c}{ CR } & \multicolumn{2}{c}{ CPA } \\
\cline { 2 - 6 } & GL & QM & P & QM & P \\
\hline Concentração & 5 & 7,67 & $<0,0001^{*}$ & 2,43 & $<0,0001^{*}$ \\
Biofertilizante & 1 & 21,70 & $<0,0001^{*}$ & 3,67 & $<0,0001^{*}$ \\
Concentração x Biofertilizante & 5 & 22,53 & $<0,0001^{*}$ & 1,62 & $<0,0001^{*}$ \\
\hline
\end{tabular}

*significativo $(p<0,05) P=$ p.value; GL Grau de Liberdade; QM Quadrado Médio

Fonte: Autores (2021)

Diferenças estatísticas foram verificadas entre os biofertilizantes $(p<0,05)$ destacando-se o biofertilizante ovino com os melhores resultados no aumento de raiz e de parte aérea das plântulas. A concentração de biofertilizante que se destacou na interação concentração x biofertilizante foi de $100 \%$.
Na Tabela 6 estão apresentados os valores médios avaliados de CR e CPA nas diferentes concentrações de biofertilizante bovino e ovino. Conforme análise estatística observou-se diferença significativa $(p<0,05)$ entre as concentrações e os biofertilizantes.

Tabela 6 - Valores médios estimados para características comprimento de raiz (CR) e da parte aérea (CRA) em centímetros para Eucalyptus camaldulensis submetida a diferentes concentrações $(0,12,5$; 25; 50; 75 e $100 \%$ ) de biofertilizante ovino e bovino

\begin{tabular}{|c|c|c|}
\hline \multirow{2}{*}{$\%$} & Ovino & Bovino \\
\hline & \multicolumn{2}{|c|}{ Comprimento de raiz (CR) } \\
\hline 0 & $1,2000 \mathrm{bA}$ & $1,2100 \mathrm{aA}$ \\
\hline 12,5 & $1,9866 \mathrm{abA}$ & $1,3966 \mathrm{aA}$ \\
\hline 25 & $1,8233 \mathrm{abA}$ & $1,0800 \mathrm{aB}$ \\
\hline 50 & $1,8633 \mathrm{abA}$ & $1,6866 \mathrm{aA}$ \\
\hline 75 & $1,8266 \mathrm{abA}$ & $1,8966 \mathrm{aA}$ \\
\hline 100 & 2,2466 aA & $1,3766 \mathrm{aB}$ \\
\hline$\%$ & \multicolumn{2}{|c|}{ Comprimento de parte aérea (CPA) } \\
\hline 0 & $0,9500 \mathrm{aA}$ & $0,9500 \mathrm{aA}$ \\
\hline 12,5 & $1,1900 \mathrm{aA}$ & $1,1366 \mathrm{aA}$ \\
\hline 25 & 1,3433 aA & $0,7466 \mathrm{aB}$ \\
\hline 50 & 1,4333 aA & $1,2966 \mathrm{aA}$ \\
\hline 75 & $1,5566 \mathrm{aA}$ & $1,1800 \mathrm{aA}$ \\
\hline 100 & $1,3700 \mathrm{aA}$ & 1,2566 aA \\
\hline
\end{tabular}

*Médias seguidas de letras iguais, minúsculas nas colunas e maiúsculas nas linhas, não diferem entre si, a $5 \%$ de probabilidade

Fonte: Autores (2021)

Os valores médios de CR demonstraram que o biofertilizante ovino, promoveu maior desenvolvimento das plântulas de eucalipto, chegando a ter uma diferença de $1,0 \mathrm{~cm}$ da concentração de $100 \%$ com relação ao controle. De acordo com Freire et al. (2010) e Pereira et al. (2010), a ação de solutos orgânicos pode propiciar alongamento celular vegetal em função da melhoria do processo de absorção de nutrientes e água. Segundo Lima et al. (2011), quando um material orgânico é adicionado ao substrato de germinação, os microrganismos realizam sua decomposição, disponibilizando 
nutrientes que promovem o maior crescimento das plantas. Nesse experimento, a adição do biofertilizante ovino proporcionou aumento no crescimento de raiz e parte aérea de eucalipto na concentração de 100\%.

Esses resultados corroboram com as observações feitas por Figueiredo et al. (2012), que utilizou o esterco de ovino e verificou aumento na produção de alface e da atividade microbiana do solo. Castilhos et al. (2007) verificaram que o vermicomposto a base de esterco ovino promoveu maior matéria seca em plantas de alface quando comparado com outros resíduos como esterco bovino, borra de café e erva mate.

Baseado nos resultados obtidos nesse experimento em condições teste de germinação, não foram verificados efeitos de toxicidade sobre a germinação e o crescimento inicial das plântulas de alface e rúcula, entretanto, a cebola apresentou redução no crescimento de raiz e de parte aérea em todas as concentrações, exceto no controle. No eucalipto, o biofertilizante ovino na concentração de $100 \%$ promoveu aumento no crescimento das plântulas.

\section{Conclusões}

Os biofertilizantes não causaram efeitos tóxicos nas espécies de alface e rúcula em condições de teste de germinação por cinco dias. Entretanto, a cebola mostrou-se sensível a aplicação, reduzindo seu crescimento de raiz e de parte aérea em todas as concentrações aplicadas, exceto no controle.

O eucalipto apresentou maior crescimento de raiz e parte aérea na concentração de $100 \%$ do biofertilizante ovino, sugerindo sua utilização na fertirrigação para produção de mudas.

Estes resultados são ainda preliminares e sugere-se mais testes com os biofertilizantes, em condições de solo com um período maior de avaliação.

\title{
5 Germination of eucalyptus and bioindicator species using two biofertilizers
}

\begin{abstract}
Biofertilizers present a viable alternative for reuse animal waste as fertilizers in agriculture. Based on this, the aim of this work was to evaluate the effect of two biofertilizers of animal origin treated in a biodigester per an ecotoxicological test using the bioindicator species Allium Cepa L. (onion); Eruca sativa L. (arugula) and Lactuca sativa $L$. (lettuce) to later test the same methodology in Eucalyptus camaldulensis Dehn. (eucalyptus) through the germination and seedling growth methods. Therefore, with biofertilizers supernatant at concentrations of 0; 12.5; 25; 50; 75 and 100\% were prepared. To assess germination, twenty seeds of each species were placed in a gerbox box containing filter paper moistened with the solution. The tests were carried out with three replications, distributed in a completely randomized design (DIC) in factorial $6 \times 2 \times 3$, with controlled temperature of $25{ }^{\circ} \mathrm{C}$ and 12 hours photoperiod, for five days. For eucalyptus the same methodology was applied, in factorial $6 \times 2$ DIC, using $0,10 \mathrm{~g}$ of seeds, at $28^{\circ} \mathrm{C}$, for 14 days. No toxicity effects on germination and initial growth of lettuce and arugula seedlings were verified. In eucalyptus, the solution containing $100 \%$ of sheep biofertilizer promoted an increase in seedling growth.
\end{abstract}

Keywords: Bovine; Sheep; Manure; Seeds; Toxicity.

\section{Referências}

ABREU, M.F.de.; ABREU JUNIOR, C.H.; SILVA, F.C. Da.; SANTOS, G.C.G.; ANDRADE, J.C.; GOMES, T.F.; COSCIONE, A.R.; ANDRADE, C.A. Análises químicas de fertilizantes orgânicos (urbanos). In: SILVA, F.C. DA. Manual de análises químicas de solos, plantas e fertilizantes do solo. 2.ed. Brasília, DF: Embrapa Informação Tecnológica, 2009. p.401-405.

AZAMBUJA, N.; HOFFMANN, C.E.F.; DAS NEVES, L.A.S.; GOULART, E.P.L. Potencial alelopático de Plectranthus barbatus Andrews na germinação de sementes de Lactuca sativa L. e de
Bidens pilosa L. Revista Ciências Agroveterinárias, n. 9 v.1, p.66-73, 2010.

BARBOSA, G.; LANGER, M. Uso de biodigestores em propriedades rurais: uma alternativa à sustentabilidade ambiental. Unoesc \& Ciência ACSA, v. 2, n. 1, p. 87-96, 2011.

BARSZCZ, L.B.; BELLATO, F.C.; BENASSI, R.F.; MATHEUS, D.R. Avaliação ecotoxicológica de efluentes tratados por alagados construídos. Engenharia Sanitária e Ambiental, v. 24, n.6, p. 1147-1156, 2019. 
BRASIL. Ministério do Meio Ambiente. Conselho Nacional do Meio Ambiente - CONAMA. Resolução $n^{\circ}$ 375, de 29 de agosto de 2006. Define critérios e procedimentos, para o uso agrícola de lodos de esgoto gerados em estações de tratamento de esgoto sanitário e seus produtos derivados, e dá outras providências. Diário Oficial da República Federativa do Brasil, Brasília, DF, 30 de agosto de 2006. Disponível em: http://www2.mma.gov.br/port/conama/res/res06/re s37506.pdf

BRASIL. Ministério do Meio Ambiente. Resolução CONAMA No 430, DE 13 DE MAIO DE 2011, Dispõe sobre as condições e padrões de lançamento de efluentes, Complementa e altera a Resolução no 357, de 17 de março de 2005, do Conselho Nacional do Meio Ambiente-CONAMA. Diário Oficial da União, Brasília, 16 de maio. 2011. Disponível em: http://www.adasa.df.gov.br/images/stories/anexos /8Legislacao/Res_CONAMA/Resolucao_CONAM A_430_2011.pdf.

BRASIL, Ministério da Agricultura e Reforma Agrária. Regras para Análise de Sementes. BRASÍLIA: 2009. 395. Disponível em: https://www.abrates.org.br/files/regras_analise_de _sementes.pdf.

CASTILHOS, D.D.; SOUZA, LM.; MORSELLI, T.B.G.A.; CASTILHOS, R.M.V. 2007. Alterações químicas no solo e produção de alface decorrentes da adição de vermicompostos. Magistra, v.19, p.143-149, 2007.

CAVALCANTE, L. F.; VIEIRA, M. S.; SANTOS, A. F.; OLIVEIRA, V. M.; NASCIMENTO, J. A. M. Água salina e esterco bovino líquido na formação de mudas de goiabeira cultivar paluma. Revista Brasileira de Fruticultura, Jaboticabal, v. 32, n. 01, p. 251-261, 2010.

EMBRAPA. Centro Nacional de Pesquisa de Solos. Manual de métodos de análise de Solo. 2 ed. rev. atual. Rio de Janeiro, 1997. 212 p. (EMBRAPA-CNPS. Documentos, 1).

FIGUEIREDO, C.C.de.; RAMOS, M.L.G.; MCMANUS, C.M.; MENEZES, A.M.de. Mineralização de esterco de ovinos e sua influência na produção de alface. Horticultura Brasileira, v.30, p. 175-179, 2012.

FREIRE, J.L.O.; CAVALCANTE, L.F.; REBEQUI, A.M.; NUNES, J.C.; DIAS, T.J.; CAVALCANTE, I. H.L. Atributos qualitativos do maracujá amarelo produzido com água salina, biofertilizante $\mathrm{e}$ cobertura morta no solo. Revista Brasileira de Ciências Agrárias, Recife, v.5, n.1, p. 102 - 110, 2010.

FUENTES, A.; LLORENS, M.; SAEZ, J.; AGUILAR, M.I.; ORTUÑO, J.F.; MESEGUER, V.F. Phytotoxicity and heavy metals speciation of stabilized sewage sludges. Journal of Hazardous Materials, v. 108, p. 161-169, 2004.

INTERNATIONAL ORGANIZATION FOR STANDARDIZATION. ISO 1269:2. Qualidade do solo - determinação dos efeitos de poluentes na flora terrestre. 2. ed. Rio de Janeiro, 2014. 23 p.

JÚNIOR, O.; MARCO, A.P.; ORRICO, A.C.A.; LUCAS JÚNIOR, J.de. Produção animal e o meio ambiente: uma comparação entre potencial de emissão de metano dos dejetos e a quantidade de alimento produzido. Engenharia Agrícola, v.31, n.2, p. 399-410, 2011.

KHADRI, M.; TEJERA, N.A. LLUCH, C. Sodium choride - ABA interaction in two common bean (Phaseolus vulgaris) cultivars differing in salinity tolerance. Environmental and Experimental Botany, n. 60, p. 211-218, 2006.

KIEHL, R.J. Manual de compostagem: maturação e qualidade do composto. 6. ed. Piracicaba: 0 autor, 2012. $171 \mathrm{p}$.

LAWLOR, D.W.; MENGEL, K.; KIRKBY, E. A. Principles of plant nutrition. Annals of Botany, v.93, n.4, p. 479-480, 2004.

LIMA, R.L.S.; SEVERINO, L.S.; SOFIATTI, V.; GHEYI, H.R.; CARVALHO JÚNIOR, G.S.; ARRIEL, N.H.C. Crescimento e nutrição de mudas de pinhão manso em substrato contendo composto de lixo orgânico. Revista Caatinga, v.24, n.3, p.167172, 2011.

MATA, J. F.; SILVA, J. C. da.; RIBEIRO, J. F.; AFFÉRRI, F. S.; VIEIRA, L. M. Produção de milho híbrido sob doses de esterco bovino. Pesquisa Aplicada \& Agrotecnologia, v.3, n.3, p.125-134, 2010.

MEDEIROS, D.C.; LIMA, B.A.B.; BARBOSA, M.R.; ANJOS, R.S.B.; BORGES, R.D.; CAVALCANTE NETO, J.G.; MARQUES, L.F. Produção de mudas de alface com biofertilizantes e substratos. Horticultura Brasileira, v.25, p. 433-436, 2007.

MIYAZAWA, M.; PAVAN, M.A.; MURAOKA, T.; CARMO, C.A.F.S.; MELO, W.J. Análise química de tecido vegetal. In: In: SILVA, F.C. DA. Manual de análises químicas de solos, plantas e fertilizantes do solo. 2.ed. Brasília, DF: Embrapa Informação Tecnológica, 2009. (p. 198-204).

NASCENTES, A.L.; PEREIRA, B.C.; PINHO, C.F. de.; SILVA, L.D.B. da.; ZONTA, E.; FERREIRA, J.A.; CAMPOS, J.C. Avaliação da toxicidade de lixiviado de aterro sanitário utilizando germinação de sementes de milho. Revista de estudos ambientais, v.21, n. 2, p.20-30, 2019.

OLIVEIRA, F. R. A.de.; OLIVEIRA, F. de A.de.; MEDEIROS, J.F. de.; SOUSA, V. de. F.L.de.; FREIRE, A.G. Interação entre salinidade e fósforo 
na cultura do rabanete. Revista Ciência Agronômica, n. 41, v.4, p. 519-526, 2010.

PEREIRA SEIDEL, E.; GONÇALVES JUNIOR, A. C.; VANIN, J. P.; STREY, L.; SCHWANTES, D.; NACKE, H. Aplicação de dejetos de suínos na cultura do milho cultivado em sistema de plantio direto. Acta Scientiarum Technology, v.32, n.2, p.113-117, 2010.

RAMIRES, M.F.; SOUZA, E.L. de; FONTANIVE, D.E.; BIANCHETTO, R.; KRYNSKI, A.M.; CEZIMBRA, J.C.G.; ANTONIOLLI, Z.I. Ecotoxicology of Pig Slaughterhouse Waste Using Lactuca sativa L., Raphanus sativus L., and Oryza sativa L. Revista Brasileira de Ciência do Solo, v. 43, e0180119, 2019.

SILVA, F.C. da.; ABREU, M.F. de. PEREZ, D.V.; EIRA, P. A. da.; ABREU, C.A. de.; RAIJ, B.V.; GIANELLLO, C.; COELHO, A.M.; QUAGGIO, J.A.; TEDESCO, M.J.; SILVA, C.A.; BARRETO, W.O. Métodos de análises químicas para a avaliação da fertilidade do solo. In: SILVA, F.C. DA. Manual de análises químicas de solos, plantas e fertilizantes do solo. 2.ed. Brasília, DF: Embrapa Informação Tecnológica, 2009. p.130-134.
SILVA, F. L. B.; LACERDA, C. F.; NEVES, A. L. R.; SOUSA, G. G.; SOUSA, C. H. C.; FEREIRA, F.J. Irrigação com águas salinas e uso de biofertilizante bovino nas trocas gasosas e produtividade de feijão-de-corda. Revista Irriga, Botucatu, v.18, n.2, p. 304-317, 2013.

SOARES, J.B.; MAIA, A.C.F. Água: microbiologia e tratamento. Fortaleza: UFC, 1999. 206p.

SOUSA, G.G. de.; VIANA, T.V. de. A.; BRAGA, E.S.; AZEVEDO, B.M.de.; MARINHO, A.B.; BORGES, F.R.M. Fertirrigação com biofertilizante bovino: Efeitos no crescimento, trocas gasosas e na produtividade do pinhão-manso. Agrária Revista Brasileira de Ciências Agrárias, v.8, n.3, p.503-509, 2013.

\section{Agradecimentos}

Os autores agradecem a professora Tânia Mara Baptista dos Santos pela doação dos biofertilizantes produzidos no laboratório de Tratamento de Resíduos da Universidade Estadual de Mato Grosso do Sul - UEMS. 